\title{
RELIGIÃO E JUVENTUDE. OS NOVOS CARISMÁTICOS [Flávio Munhoz Sofiati, 2011, São Paulo, Brasil, Editora Ideias \& Letras / FAPESP]
}

\author{
José Pereira Coutinho
}

Númena. Porto Salvo, Portugal.

Do cruzamento entre religião e juventude, surge a tese de doutoramento em sociologia (Universidade de São Paulo), agora apresentada neste livro. O autor, Flávio M. Sofiati, professor adjunto da Universidade Federal de Goiás, percorre com segurança estes dois domínios sociológicos: a sua experiência e conhecimento autorizam-no. A escolha da Renovação Carismática Católica (RCC) brasileira como objeto de estudo, apostando, como campo de observação, numa cidade de tamanho médio, parece adequada, pela falta de pesquisas respetivas. Para o autor, o estudo justifica-se pelo aumento das correntes pentecostais nos últimos vinte anos e pela sua influência crescente na sociedade brasileira. $O$ vazio deixado nos jovens brasileiros pela "precariedade da educação, a restrição do emprego e o esvaziamento ideológico da política" valoriza esta tese, por querer compreender como a Igreja Católica (IC), através da RCC, o preenche. Suportando-se em Weber e Gramsci, Sofiati pode afirmar que a religião serve como lenitivo ao sofrimento, principalmente nas classes desfavorecidas, as maiores "clientes" da RCC. Depois de demonstrar que o povo brasileiro nunca foi desencantado, mas tão-somente o foram as variadas esferas sociais, e de defender que os carismáticos encantam o mundo pelos seus valores e pelas suas práticas, o autor pretende estudá-los, querendo explicar a atração dos jovens por este movimento.

Será que Sofiati alcançou o objetivo proposto? A resposta positiva baseia-se no manancial de informação exposta e coligida de fontes diversas de forma coerente e lógica. O perfil do jovem carismático torna-se claro, sintetizado no capítulo final. Ademanda por um projeto de vida, longe do risco, motiva os jovens na procura da RCC. A vivência imbuída de Espírito Santo e dos seus carismas, a obediência, a castidade, o afastamento do mundo, a busca da santidade, são marcas da RCC. Conclui-se, todavia, que, pelo choque entre as esferas erótica e religiosa, a permanência no movimento seja maioritariamente curta. "Porque são muitos os chamados mas poucos os escolhidos" (Mt. 22, 14). Naturalmente que os leigos, mais distantes do sagrado, não o compreendem tão bem, nem às suas exigências, para lhe ficarem fiéis.

A leitura do livro impõe três tipos de observações: formais, teóricas e metodológicas. Em termos formais, o livro apresenta um estilo bem conseguido, embora atenuado por repetições ao longo do texto. Em termos teóricos, evidencia-se a escolha ajustada dos autores. A discussão sobre a religião no capítulo 2 foi acertada pela mestria de Weber e pelo acolhimento pertinente de Gramsci, algo raro na sociologia da religião. O debate interessante e completo no capítulo 3 sobre o encantamento e a secularização do cenário religioso brasileiro clarifica-o. Ainda, a relevância 
dos estudos citados sobre o pentecostalismo, tanto católico como evangélico, demonstra o domínio da área. Em termos metodológicos, surgem alguns comentários. Primeiro, a escolha do referente empírico afigura-se pertinente, por a juventude se encontrar com graves carências educacionais, profissionais e afetivas e, por isso, mais aberta às ofertas religiosas. Segundo, a escolha da Canção Nova (CN), composta maioritariamente de jovens, do movimento juvenil Por Hoje Não vou mais Pecar (PHN) e do grupo de oração Novo Pentecostes (NP) foram igualmente opções acertadas, pela sua importância no seio da RCC. Terceiro, nas passagens sobre os líderes carismáticos Dunga e Claudinei, o texto seria ainda mais rico e a sua credibilidade maior se aparecessem comentários de pessoas exteriores ao movimento, tanto os que já tinham pertencido, como elementos externos, pertencentes ou não à IC. No fundo, dar voz tanto a insiders como a outsiders.

Percorrendo agora os capítulos, no primeiro, o autor justifica a preponderância dos movimentos carismáticos junto da juventude brasileira católica atual. Sofiati começa por percorrer resumidamente a história dos movimentos juvenis brasileiros no século XX, afirmando o domínio dos movimentos religiosos na socialização atual juvenil, principalmente nos de cariz pentecostal. Nestes, os jovens podem, não só ter as suas experiências radicais de encontro com o sobrenatural, mas também encontrar formas de superar as suas frustrações, ligadas às questões da educação, do trabalho e da política. Por isso, os jovens envolvidos são maioritariamente desfavorecidos, desempregados, de baixa escolaridade e com fraca ou nenhuma participação política. A argumentação desenvolve-se mostrando que as carências destes jovens na educação e no trabalho condicionam o seu interesse pela política. Assim, as suas perspetivas de futuro são menores, havendo duas alternativas: a perdição ou a salvação. Esta passa pela descoberta de um projeto de vida no seio dos movimentos pentecostais, nos quais os jovens encontram a sua identidade e a sua autonomia, para além das suas experiências. Eventualmente a questão da salvação junto dos movimentos pentecostais poderia ser mais apurada, pois parece que fora deles ela não existe.

No capítulo 2, Sofiati apresenta os conceitos de juventude e de religião. A discussão sobre o conceito de juventude poderia ser colocada no começo do capítulo anterior, onde se trata exclusivamente do mesmo. Além disso, faltou defini-la, como estádio de passagem à condição adulta sem as responsabilidades inerentes a esta (trabalho, conjugalidade, casa e filhos). Ainda, o conceito de juventude poderia ser mais explorado, nomeadamente no seu surgimento como categoria própria das sociedades modernas. A abordagem teórica sobre a religião parece acertada, embora o autor ao mostrar os contributos de Weber e de Gramsci, de três formas diferentes, os repita parcialmente. Após desenvolver os conceitos de forma isolada e de analisar os aspetos comuns, Sofiati discorre sobre a sua aplicação no seu estudo. Assim, em Weber os conceitos de tipo ideal de ação são essenciais: a ação dos jovens carismáticos modela-se pela racionalidade de fins e de valores, embora sejam referidas razões afetivas ou consuetudinárias na constituição das comunidades eclesiais. Os tipos ideais de dominação (racional, tradicional e carismática) são também importantes para analisar as lideranças, concluindo que a $\mathrm{CN}$ possui liderança carismática, embora permeada de aspetos racionais e tradicionais. Por último, as 
definições de vários conceitos relativos a elementos, práticas e atores são igualmente relevantes. Nos atores, os leigos, pelas suas carências socioeconómicas buscam não uma ética, mas a promessa de retribuição pelo seu sofrimento. A relação entre os sacerdotes e os leigos também importa, enfatizando a forma como os conteúdos religiosos condicionam a ação juvenil. Com Gramsci, o autor pretende estudar a religião como ideologia, ou seja, a IC como aparelho ideológico e, a partir desta perspetiva, analisar os intelectuais religiosos e as suas relações com o estado.

No capítulo 3, o autor aborda o cenário religioso brasileiro. Começa por discutir a relação entre racionalização, desencantamento e secularização, baseando-se em Weber, Berger e Pierucci, e concluindo que a racionalização conduziu ao desencantamento e este à secularização. Passando à discussão sobre a dessecularização, por o panorama brasileiro a tal o obrigar, Berger vem em seu auxílio, afirmando que aquela ocorre nas religiões que rejeitam o mundo moderno, como o islamismo e o evangelismo. De seguida, coloca a questão de saber como ocorreu o reencantamento no Brasil: o sociólogo Negrão defende que no Brasil somente as diferentes esferas sociais foram racionalizadas e, por isso, foram secularizadas, enquanto a mentalidade do povo se manteve encantada. Assim se explica o sucesso dos movimentos pentecostais, plenos de emotividade e encantamento. Olhando agora para o pluralismo religioso, o autor discute-o à luz das teorias da secularização e da escolha racional, concluindo pela insuficiência das duas, se não atenderem ao grau de regulação do mercado. Este novo modelo permite explicar o caso brasileiro, no qual, apesar da diminuição da regulação do mercado religioso, ainda existem custos sociais consideráveis nas mudanças religiosas, pelo que o catolicismo mantém presença forte. Ao mesmo tempo, observa-se a grande diversidade dentro da IC. Por último, Sofiati classifica a RCC baseando-se em quatro autores. Segundo a classificação de Lowy, a RCC é um movimento modernizador-conservador. Mas aqui o autor abrevia o discurso. Primeiro, dos quatro cenários de Libanio e de Boff não se refere quais se encontram na RCC. Segundo, não se explica como as três tendências de Gramsci se encontram nas quatro tendências de Lowy. Terceiro, a descrição da tendência modernizadora-conservadora poderia ser alongada.

No capítulo 4, o autor avança com a história do pentecostalismo católico. Aqui, partindo do contexto mundial, passa para o cenário brasileiro, onde, em algumas páginas, descreve a evolução da RCC brasileira e os elementos característicos de cada fase. Qualifica depois a teologia carismática, assente em dois pontos essenciais: a vida nova fruto da conversão e da receção do batismo no Espírito Santo, e os carismas ou dons. Passa então a debater a relação da RCC com a IC brasileira. Embora seja reconhecida a importância da RCC no rejuvenescimento católico, a hierarquia aponta algumas preocupações, relacionadas com o exacerbamento da emoção, a manipulação dos dons, a leitura livre da Bíblia, a transformação das missas em grupos de oração, o desligamento paroquial. Sofiati descreve depois a relação da RCC com a política, mostrando que este movimento tenta criar lideranças políticas carismáticas, as quais têm defendido as posições da IC, principalmente nas questões da vida e da sexualidade, demarcando-se como conservador. $\mathrm{O}$ autor termina afirmando que a RCC tem um papel essencial no catolicismo brasileiro, ao contrário de movimentos de cariz radical como a Teologia da Libertação. Como 
defende Sofiati, a PHN vai ao encontro das necessidades dos jovens atuais: sentido, profissional, financeira, afetiva, familiar e identitária.

No capítulo 5, Sofiati passa então para o terreno. Caracteriza o movimento $\mathrm{PHN}$, pertencente à CN. Primeiro, começa por analisar a organização da juventude carismática, a qual se divide em estruturas responsáveis pela oração jovem, pela oração universitária (ou dos recentemente diplomados) e pela música. Segundo, versa as comunidades carismáticas da RCC existentes no Brasil, terminando pela descrição da CN. Esta é a comunidade pioneira da RCC, composta maioritariamente por jovens, na qual se pretende viver o ideal da Igreja primitiva, apostando no sentido comunitário e na missão através da comunicação social e da organização de eventos. Finalmente Sofiati apresenta o setor juvenil da CN, o PHN. Este grupo fundamenta-se no conhecimento de Jesus Cristo para a libertação do pecado, o qual radica principalmente na sexualidade afastada das normas católicas. Depois dá-se a palavra ou discorre-se sobre o fundador do PHN, Dunga, cuja conversão e empenho assiste de exemplo aos jovens. Sofiati prossegue mencionando os exemplos bíblicos de conversão e de seguimento fiel da doutrina sexual e a importância dada pela PHN à castidade, a qual serve para demonstrar a centralidade da submissão dos jovens aos líderes e a presença dominante da liderança carismática no PHN. Passa depois a descrever os instrumentos para libertação do pecado: oração do Rosário, comunhão diária, leitura da Bíblia, jejum e confissão. O autor socorre-se de Weber para explicar a razão do diferendo entre religião e sexualidade: basicamente as duas esferas chocam por serem autónomas e por a sexualidade ser mais atrativa principalmente nos jovens. Por último, Sofiati refere que o PHN é bandeira da RCC, na qual existe um tipo ideal de jovem, aquele que diariamente diz não ao pecado. Depois de referir a importância da pertença às comunidades, do exemplo, da emoção, da heroicidade e da disciplina, o autor acaba afirmando que a vivência comunitária, pautada pela emoção, oferece ao jovem sem perspetivas de futuro uma vida livre de pecado, embora isolada do mundo.

O capítulo 6 abre com a descrição dos jovens do município de Araraquara, antes de se começar a analisar o NP, referindo-se variáveis úteis para este estudo. A escolha do NP deve-se ao facto de ser o mais identificado com o PHN, onde se discute a sexualidade, onde a música é essencial e onde ocorreram disputas com outros setores católicos, permitindo examiná-las. Existem quatro momentos do grupo à volta da oração: para as lideranças, para os membros, para o público em geral e pela rádio. Sofiati descreve como decorrem as reuniões semanais para o público em geral, caracterizadas pela devoção a Maria, louvores e testemunhos de curas e orações coletivas em línguas, num ambiente emotivo. De seguida, analisa-se o líder do NP, Claudinei. Sofiati discorre depois sobre a centralidade da música no PHN, abordando principalmente a música Restauração, instrumento de conversão: o paralelismo entre a dor de Dunga ao escrever a música e a dos que se convertem é referido. Passa depois para uma comparação do NP com o grupo de oração carismático Plenitude de Paris, focando-se na questão do transe corporal, algo polémico no NP. A questão da permanência no NPé tão significativa que Sofiati disserta repetidamente (três vezes) sobre a mesma em pontos diferentes deste capítulo, concluindo pela rotatividade grande, devido a questões de afetividade e de sexualidade. E termina-se esta recensão com a 
questão erótica, pois, da leitura deste livro, a conclusão mais clara é a seguinte: pela tomada exigente das posições católicas sobre a sexualidade, os leigos não aguentam o fardo dos eleitos (sacerdotes, profetas ou magos), sendo a sua permanência curta.

José Pereira Coutinho (corresponding author). Investigador da Númena.

Doutorado em sociologia (ISCTE-IUL). Taguspark - Núcleo central, 379, 2740-122,

Porto Salvo. E-mail: jose.coutinho@numena.org.pt 